\title{
Cerebrovascular accidents complicating transcatheter aortic valve implantation: frequency, timing and impact on outcomes
}

\author{
Stefan Stortecky ${ }^{1}, \mathrm{MD}$; Stephan Windecker ${ }^{1,2 *}, \mathrm{MD}$; Thomas Pilgrim¹, MD; Dik Heg², PhD; \\ Lutz Buellesfeld ${ }^{1}$, MD; Ahmed A. Khattab ${ }^{1}$, MD; Christoph Huber ${ }^{3}$, MD; Steffen Gloekler ${ }^{1}$, MD; \\ Fabian Nietlispach ${ }^{1}$, MD; Heinrich Mattle ${ }^{4}$, MD; Peter Jüni ${ }^{2}$, MD; Peter Wenaweser ${ }^{1}$, MD
}

1. Department of Cardiology, Swiss Cardiovascular Centre, Bern University Hospital, Bern, Switzerland; 2. Clinical Trials Unit, Bern, Switzerland; 3. Department of Cardiovascular Surgery, Swiss Cardiovascular Centre, Bern University Hospital, Bern, Switzerland; 4. Department of Neurology, Bern University Hospital, Bern, Switzerland

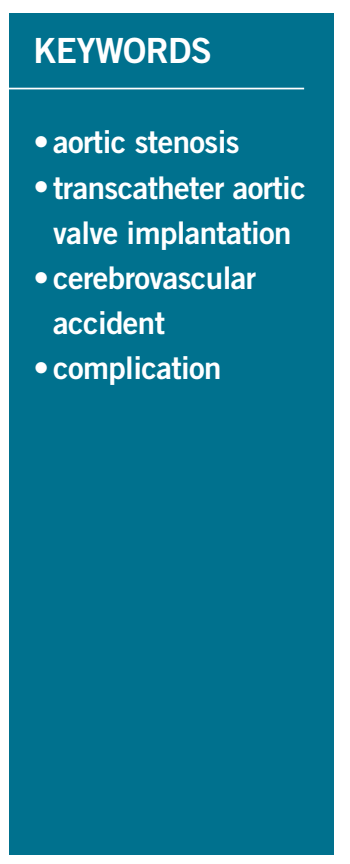

\begin{abstract}
Aims: Cerebrovascular accidents (CVA) are considered among the most serious adverse events after transcatheter aortic valve implantation (TAVI). The objective of the present study was to evaluate the frequency and timing of CVA after TAVI and to investigate the impact on clinical outcomes within 30 days of the procedure.
\end{abstract}

Methods and results: Between August 2007 and October 2011, 389 high-risk elderly patients with symptomatic severe aortic stenosis underwent TAVI via transfemoral, transapical or subclavian access. A total of 14 patients (3.6\%) experienced at least one CVA within 30 days of follow-up and most events (74\%) occurred within the first day of the procedure. Patients with CVA had an increased risk of all-cause ( $42.3 \%$ vs. $5.1 \%$, $\mathrm{OR}_{\text {adjusted }} 11.7,95 \%$ CI 3.4-40.3, p $\left.<0.001\right)$ and cardiovascular mortality $\left(38.4 \%\right.$ vs. $4.6 \%$, OR adjusted $_{10.5,95 \%}$ CI 2.9-37.8, $\mathrm{p}<0.001)$ compared to patients without CVA at 30 days of follow-up. Repeated device implantation attempts $\left(\mathrm{OR}_{\text {adjusted }} 8.3, \mathrm{CI} 2.1-33.3, \mathrm{p}<0.003\right)$, chronic pulmonary disease $\left(\mathrm{OR}_{\text {adjusted }}\right.$ 4.7, CI 1.3-16.8, $\mathrm{p}=0.02)$ and body mass index $<25 \mathrm{~kg} / \mathrm{m}^{2}\left(\mathrm{OR}_{\text {adjusted }} 0.8\right.$, CI $\left.0.7-0.9, \mathrm{p}<0.01\right)$ emerged as independent predictors of periprocedural CVA.

Conclusions: Cerebrovascular accidents among patients undergoing TAVI occur predominantly during the periprocedural period, are associated with multiple implantation attempts of the bioprosthesis and significantly impair prognosis.

\footnotetext{
*Corresponding author: Department of Cardiology, Bern University Hospital, CH-3010 Bern, Switzerland. E-mail: stephan.windecker@insel.ch
} 


\section{Introduction}

Transcatheter aortic valve implantation (TAVI) has rapidly evolved into a valuable treatment option for selected patients with severe, symptomatic degenerative aortic stenosis. As compared with medical treatment, TAVI improves survival and reduces the need for hospitalisation among patients no longer deemed to be surgical candidates $^{1}$. In addition, TAVI has been shown to be non-inferior in terms of survival compared with surgical aortic valve replacement (SAVR) among selected, high-risk patients ${ }^{2}$. The favourable clinical outcome of TAVI in randomised trials is supplemented by effective alleviation of symptoms, improvements of health-related quality of life and presence of cost-effectiveness ${ }^{3,4}$.

Careful patient selection, growing operator experience and ongoing improvements of transcatheter heart valve devices and technique have led to a substantial reduction of periprocedural complications. Notwithstanding, cerebrovascular accidents (CVA) remain among the most feared adverse events from a patient perspective, as they may result in total or partial loss of independence in everyday life. In addition, CVAs have an important impact on morbidity and mortality depending on the size and location of infarcted cerebral tissue. In the randomised Placement of Transcatheter Aortic Valves (PARTNER A) trial, patients allocated to TAVI had a trend towards a higher risk of major stroke compared with SAVR at one year, raising the question whether the procedure itself, the implanted prostheses or the antithrombotic treatment may influence the risk of CVAs ${ }^{5}$. The purpose of the present study was to describe the frequency and timing of periprocedural CVAs among consecutive, high-risk patients undergoing TAVI and to investigate their impact on clinical outcomes.

\section{Methods}

\section{STUDY DESIGN AND PATIENT POPULATION}

Between August 2007 and October 2011, 389 high-risk elderly patients with symptomatic severe aortic stenosis of the native valve were included into a prospective single-centre registry (Bern TAVI registry). Patients underwent TAVI with the self-expandable Medtronic CoreValve (MCV; Medtronic, Minneapolis, MN, USA) or the balloon-expandable Edwards SAPIEN transcatheter heart valve (ES; Edwards Lifesciences, Irvine, CA, USA) using the transfemoral, the transapical and the subclavian access routes as previously described ${ }^{6}$. Device and access route selection was based on individual anatomical characteristics and technical specifications of the prostheses. Patients were assigned to undergo a TAVI procedure following consensual agreement by the local Heart Team consisting of invasive cardiologists and cardiac surgeons.

The TAVI procedure was primarily performed using percutaneous femoral access, balloon predilatation of the stenotic valve following implantation of the prosthesis under conscious sedation or general anaesthesia. After the procedure, patients were admitted to a coronary care unit and monitored during the following 48 hours for rhythm disturbances, neurological deficits, vascular access site complications and other adverse events. In case of a suspected cerebrovascular event, patients were assessed by a board-certified neurologist and underwent neuroimaging by use of contrastenhanced computed tomography or magnetic resonance tomography. The type and sequence of different imaging modalities (CT scan or MRI) among patients with suspected stroke were determined by the neurologist.

All patients were treated with acetylsalicylic acid $100 \mathrm{mg}$ per day indefinitely and clopidogrel $75 \mathrm{mg}$ per day for six months. Clopidogrel loading (600 mg) was performed one day prior to the procedure in patients who were not on chronic thienopyridine therapy. In case of indication for oral anticoagulation, warfarin was combined with either acetylsalicylic acid or clopidogrel alone.

The study complied with the declaration of Helsinki and the registry was approved by the local medical ethics committee. All patients provided written informed consent to participate in the registry and to undergo prospective follow-up. The authors are solely responsible for the design and the conduct of this study, the study analyses, the drafting and editing of the paper and gave approval for its final content.

\section{DATA COLLECTION}

Patients were categorised into two study groups: (I) patients suffering at least one CVA within 30 days of the procedure (CVA), and (II) patients without CVA during the first thirty days (No CVA). Adverse events were assessed in hospital, and regular clinical follow-up was performed at 30 days and 12 months by means of a clinical in-hospital visit or a standardised telephone interview. All suspected adverse events were adjudicated by an unblinded clinical event committee consisting of interventional cardiologists and cardiac surgeons. In case of suspected cerebrovascular events, patients were assessed by a board-certified neurologist and underwent neurological imaging studies as indicated. The neurological events were adjudicated in consensus and guided by the expert neurological assessment according to the endpoint definitions proposed by the Valve Academic Research Consortium (VARC). Baseline clinical and procedural characteristics as well as follow-up data were entered into a dedicated database, held at an academic clinical trials unit (Cardiobase, CTU Bern, Bern University Hospital, Switzerland) responsible for central data audits and maintenance of the database.

\section{DEFINITIONS}

Clinical adverse events were adjudicated according to the endpoint definitions proposed by VARC, described in detail elsewhere ${ }^{7}$. Cerebrovascular accidents (CVA) were defined as the composite of major stroke, minor stroke or transient ischaemic attack (TIA). Stroke was defined as a rapid onset of a focal or global neurological deficit with change in level of consciousness, hemiplegia, hemiparesis, numbness or sensory loss affecting one side of the body, dysphasia or aphasia, hemianopia, amaurosis fugax or other neurological signs or symptoms consistent with stroke and confirmed by a neurology specialist as well as neuroimaging. The severity of the event was classified according to the Modified Rankin Scale. A stroke was considered major in the presence of a calculated Modified Rankin score of $\geq 2$ and minor in the presence 
of a calculated Modified Rankin score $<2$. TIA was defined as a new focal neurological deficit as indicated above with rapid symptom resolution within 24 hours in the absence of cerebral tissue injury as evidenced by neuroimaging.

The number of predilations of the native valve and post-dilations after bioprosthesis implantation were recorded. In addition, the number of implantation attempts was assessed by counting the frequency of valve prosthesis placement attempts prior to obtaining the final implantation result.

\section{STATISTICAL ANALYSIS}

Patient demographics and procedural and follow-up data were prospectively collected and entered in a dedicated database held at CTU Bern, Switzerland. All statistical analyses were performed by a statistician of an academic clinical trials unit (DH and PJ, Clinical Trials Unit Bern, Bern University Hospital, Switzerland) using Stata 12 (StataCorp LP, College Station, TX, USA). Continuous variables are presented as mean $\pm \mathrm{SD}$ and are compared by means of unpaired t-tests. Categorical data are expressed as frequencies and percentages and are compared using $\chi^{2}$ and Fisher's exact tests. Time to death was compared between the CVA and No CVA group using a Mantel-Cox log-rank test and presented with Kaplan-Meier curves. Endpoints up to 30 days follow-up were analysed with logistic regression (crude analyses) and with logistic regression adjusting for the effects of body mass index and chronic obstructive pulmonary disease (adjusted analyses). Endpoints up to 30 days follow-up with zero events in one group were analysed with exact logistic regression (crude analyses).

\section{Results \\ PATIENT POPULATION}

Between August 2007 and October 2011, 389 consecutive patients underwent TAVI for native aortic valve stenosis using the transfemoral, transapical or subclavian access route. During the periprocedural period up to 30 days of follow-up, a total of 14 patients (3.6\%) experienced at least one CVA, which consisted of a major stroke in 12 patients $(3.1 \%)$ and a minor stroke in 2 patients $(0.5 \%)$. The vast majority of CVAs occurred during or within one day of the procedure (Figure 1) (71.4\%; major stroke, $n=8$; minor stroke, $\mathrm{n}=2$ ). Baseline characteristics of patients with as compared to patients without periprocedural CVA are shown in Table 1. Patients suffering from CVA had a smaller body mass index $(22.9 \% \pm 2.6 \mathrm{vs}$. $26.3 \% \pm 5.1, \mathrm{p}=0.01)$ and tended to have a higher incidence of prior stroke $(21 \%$ vs. $7 \%, \mathrm{p}=0.08)$ and chronic obstructive pulmonary disease $(38 \%$ vs. $18 \%, \mathrm{p}=0.08)$ in their past medical history as compared to patients without CVA. Other risk factors for stroke including age $(81.5 \pm 6.7$ vs. $82.5 \pm 5.8, \mathrm{p}=0.51)$, male gender $(64 \%$ vs. $49 \%, \mathrm{p}=0.26$ ), arterial hypertension ( $86 \%$ vs. $78 \%, \mathrm{p}=0.74)$, diabetes mellitus ( $14 \%$ vs. $27 \%, p=0.37)$, smoking ( $21 \%$ vs. $12 \%$, $\mathrm{p}=0.40)$ and atrial fibrillation ( $36 \%$ vs. $27 \%, \mathrm{p}=0.54)$ were not different between the two groups. The overall surgical risk of the present patient cohort was high as estimated by a mean EuroSCORE of

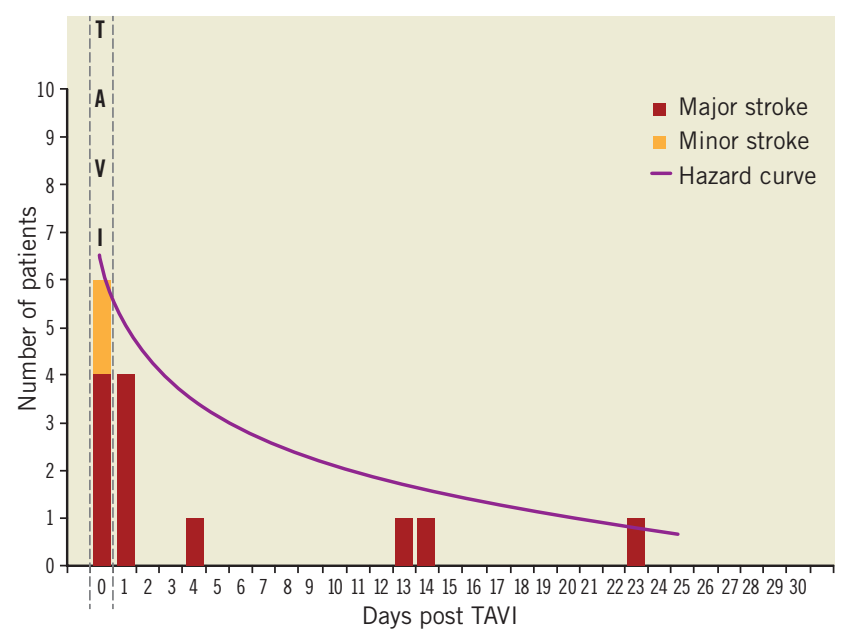

Figure 1. Frequency distribution of cerebrovascular accidents within 30 days after transcatheter aortic valve implantation.

$24.3 \pm 14.2 \%$ and a mean STS Score of $6.8 \pm 5.3 \%$ without apparent differences between patients with and without CVA during the periprocedural follow-up period. There were also no differences with respect to antithrombotic treatment at baseline between the two groups.

\section{PROCEDURAL CHARACTERISTICS}

Procedural characteristics are summarised in Table 2. The most frequently applied implantation strategy was the retrograde, transfemoral access route $(n=308,79 \%)$, followed by the transapical $(n=76,20 \%)$ and subclavian access site $(n=5,1 \%)$. All patients underwent TAVI with either the Medtronic CoreValve $(n=224,58 \%)$ or the Edwards SAPIEN transcatheter heart valve prosthesis $(n=165,42 \%)$ with no differences between the two groups. The vast majority of patients underwent balloon dilatation of the native valve prior to valve implantation ( $\mathrm{n}=385,99 \%)$ with 56 patients $(14 \%)$ requiring more than one predilatation, whereas 4 patients $(1 \%)$ were treated without balloon predilatation. Post-dilatation after placement of the transcatheter heart valve prosthesis was performed in 108 patients (28\%), and implantation of more than one valve in series was required in 7 patients $(2 \%)$. Neither the number of predilatations nor the implantation of more than one valve in series resulted in a higher number of CVAs. Conversely, more than one device implantation attempt was more commonly counted among patients with as compared to patients without CVA ( $29 \%$ vs. $8 \%, p=0.023$ ). Similarly, there was a trend towards more post-dilatations among patients with than without CVA ( $50 \%$ vs. $27 \%$, $\mathrm{p}=0.072$ ). Although fluoroscopy time was longer in the CVA group ( $25 \pm 14 \mathrm{~min}$ vs. $20 \pm 10 \mathrm{~min}, \mathrm{p}=0.05$ ), no differences were recorded in terms of procedural time ( $89 \pm 52 \mathrm{~min}$ vs. $83 \pm 35 \mathrm{~min}, \mathrm{p}=0.53$ ), amount of contrast agent $(287 \pm 127 \mathrm{ml}$ vs. $251 \pm 95 \mathrm{ml}, \mathrm{p}=0.17)$ and treatment of concomitant coronary artery disease $(14 \%$ vs. $16 \%, p=1.00)$. The antithrombotic regimen at time of discharge is shown in Table 3 without significant differences in use of acetylsalicylic acid, thienopyridines, dual antiplatelet therapy, and oral anticoagulation between 
Table 1. Baseline clinical characteristics.

\begin{tabular}{|c|c|c|c|c|}
\hline & $\begin{array}{l}\text { All patients } \\
(n=389)\end{array}$ & $\begin{array}{c}\text { CVA } \\
(n=14)\end{array}$ & $\begin{array}{c}\text { No CVA } \\
(n=375)\end{array}$ & $p$-value \\
\hline Age (years) & $82.5 \pm 5.8$ & $81.5 \pm 6.7$ & $82.5 \pm 5.8$ & 0.51 \\
\hline Female gender, $\mathrm{n}(\%)$ & $197(51 \%)$ & $5(36 \%)$ & $192(51 \%)$ & 0.26 \\
\hline Body mass index $\left(\mathrm{kg} / \mathrm{m}^{2}\right)$ & $26.2 \pm 5.1$ & $22.9 \pm 2.6$ & $26.3 \pm 5.1$ & 0.01 \\
\hline \multicolumn{5}{|l|}{ Cardiac risk factors } \\
\hline Diabetes mellitus, $\mathrm{n}(\%)$ & $105(27 \%)$ & $2(14 \%)$ & $103(27 \%)$ & 0.37 \\
\hline Hypercholesterolaemia, n (\%) & $236(61 \%)$ & $9(64 \%)$ & $227(61 \%)$ & 0.79 \\
\hline Hypertension, n (\%) & $303(78 \%)$ & $12(86 \%)$ & $291(78 \%)$ & 0.74 \\
\hline Current smoker, n (\%) & $48(12 \%)$ & $3(21 \%)$ & $45(12 \%)$ & 0.40 \\
\hline \multicolumn{5}{|l|}{ Past medical history } \\
\hline Previous myocardial infarction, $\mathrm{n}(\%)$ & $64(16 \%)$ & $2(14 \%)$ & $62(17 \%)$ & 1.00 \\
\hline Previous coronary artery bypass graft, $\mathrm{n}(\%)$ & $72(19 \%)$ & $2(14 \%)$ & $70(19 \%)$ & 1.00 \\
\hline Previous percutaneous coronary intervention, $\mathrm{n}(\%)$ & $94(24 \%)$ & $2(14 \%)$ & $92(25 \%)$ & 0.53 \\
\hline Previous stroke, n (\%) & $30(8 \%)$ & $3(21 \%)$ & $27(7 \%)$ & 0.08 \\
\hline Peripheral vascular disease, $\mathrm{n}(\%)$ & $87(22 \%)$ & $1(7 \%)$ & $86(23 \%)$ & 0.21 \\
\hline Chronic obstructive pulmonary disease, n (\%) & $72(19 \%)$ & $5(38 \%)$ & $67(18 \%)$ & 0.08 \\
\hline Atrial fibrillation, n (\%) & $103(27 \%)$ & $5(36 \%)$ & $98(27 \%)$ & 0.54 \\
\hline \multicolumn{5}{|l|}{ Clinical features } \\
\hline Renal failure (GFR<60 ml/min/1.73 m²) & $268(69 \%)$ & $11(79 \%)$ & $257(69 \%)$ & 0.56 \\
\hline Coronary artery disease, $\mathrm{n}(\%)$ & $238(61 \%)$ & $6(43 \%)$ & $232(62 \%)$ & 0.15 \\
\hline Left ventricular ejection fraction (\%) & $51.9 \pm 14.8$ & $50.0 \pm 16.7$ & $51.9 \pm 14.7$ & 0.63 \\
\hline Aortic valve area $\left(\mathrm{cm}^{2}\right)$ & $0.6 \pm 0.2$ & $0.6 \pm 0.3$ & $0.6 \pm 0.2$ & 0.88 \\
\hline Mean transaortic gradient (mmHg) & $44.2 \pm 16.8$ & $46.8 \pm 19.8$ & $44.1 \pm 16.7$ & 0.56 \\
\hline \multicolumn{5}{|l|}{ Symptoms } \\
\hline New York Heart Association (NYHA) Functional Class & & & & 0.88 \\
\hline NYHA I, n (\%) & $22(6 \%)$ & $1(7 \%)$ & $21(6 \%)$ & \\
\hline NYHA II, n (\%) & $109(28 \%)$ & $5(36 \%)$ & $104(28 \%)$ & \\
\hline NYHA III, n (\%) & $206(53 \%)$ & $6(43 \%)$ & $200(54 \%)$ & \\
\hline NYHA IV, n (\%) & $49(13 \%)$ & $2(14 \%)$ & $47(13 \%)$ & \\
\hline \multicolumn{5}{|l|}{ Risk assessment } \\
\hline Logistic EuroSCORE (\%) & $24.3 \pm 14.2$ & $28.7 \pm 21.7$ & $24.1 \pm 13.8$ & 0.23 \\
\hline STS Score (\%) & $6.8 \pm 5.3$ & $8.8 \pm 8.9$ & $6.7 \pm 5.1$ & 0.16 \\
\hline \multicolumn{5}{|l|}{ Antithrombotic therapy } \\
\hline Aspirin, n (\%) & $237(62 \%)$ & $8(62 \%)$ & $229(62 \%)$ & 1.00 \\
\hline Clopidogrel, n (\%) & $69(18 \%)$ & $1(8 \%)$ & $68(18 \%)$ & 0.48 \\
\hline Oral anticoagulation, n (\%) & $106(28 \%)$ & $3(23 \%)$ & $103(28 \%)$ & 1.00 \\
\hline
\end{tabular}

patients with and without CVA. In multivariable logistic regression analysis, more than one device implantation attempt $\left(\mathrm{OR}_{\text {adjusted }} 8.3, \mathrm{CI}\right.$ 2.1-33.3, $\mathrm{p}=0.003)$, chronic obstructive pulmonary disease $\left(\mathrm{OR}_{\text {adjusted }}\right.$ 4.7, CI 1.3-16.8, $\mathrm{p}=0.02$ ) and body mass index $<25 \mathrm{~kg} / \mathrm{m}^{2}\left(\mathrm{OR}_{\text {adjusted }}\right.$ 0.8 , CI $0.7-0.9, \mathrm{p}=0.01$ ) emerged as independent predictors of periprocedural CVA (Table 4).

\section{CLINICAL OUTCOMES}

Clinical outcomes through 30 days of follow-up according to VARC are summarised in Table 4. Overall and cardiovascular mortality amounted to $6.4 \%$ and $5.7 \%$, respectively, at 30 days in this patient population. Patients with CVA during the periprocedural period had an increased risk of all-cause (42.3\% vs. $5.1 \%$, $\mathrm{OR}_{\text {adjusted }} 11.7,95 \%$ CI 3.4-40.3, $\left.\mathrm{p}<0.001\right)$ and cardiovascular death $\left(38.4 \%\right.$ vs. $4.6 \%, \mathrm{OR}_{\text {adjusted }} 10.5,95 \%$ CI $\left.2.9-37.8, \mathrm{p}<0.001\right)$ compared to patients without CVA in crude and adjusted analyses (Figure 2). There were no differences in the risk of myocardial infarction ( $0 \%$ vs. $0.5 \%, \mathrm{OR}_{\text {crude }} 11.2,95 \%$ CI $\left.0.0-146.9, \mathrm{p}=1.00\right)$, bleeding complications (life-threatening bleeding $7 \%$ vs. $17 \%$, $\mathrm{OR}_{\text {adjusted }} 0.4,95 \%$ CI $\left.0.05-3.3, \mathrm{p}=0.40\right)$, acute renal failure $(7 \%$ 
Table 2. Procedural characteristics.

\begin{tabular}{|c|c|c|c|c|}
\hline & $\begin{array}{c}\text { All patients } \\
(\mathrm{n}=389)\end{array}$ & $\underset{(n=14)}{\text { CVA }}$ & $\begin{array}{c}\text { No CVA } \\
(n=375)\end{array}$ & $p$-value \\
\hline Procedure time (min) & $82.7 \pm 35.4$ & $88.8 \pm 51.7$ & $82.5 \pm 34.7$ & 0.53 \\
\hline Fluoroscopy time (min) & $19.8 \pm 10.3$ & $25.1 \pm 14.3$ & $19.6 \pm 10.1$ & 0.049 \\
\hline Amount of contrast (ml) & $252.2 \pm 96.7$ & $287.0 \pm 127.0$ & $250.9 \pm 95.3$ & 0.17 \\
\hline General anaesthesia, $n(\%)$ & $164(42 \%)$ & $4(29 \%)$ & $160(43 \%)$ & 0.41 \\
\hline New-onset atrial fibrillation, $n$ (\%) & $27(7 \%)$ & $0(0 \%)$ & $27(7 \%)$ & 0.61 \\
\hline \multicolumn{5}{|l|}{ Access route } \\
\hline Femoral, $n(\%)$ & $308(79 \%)$ & $12(86 \%)$ & $296(79 \%)$ & 0.74 \\
\hline Apical, n (\%) & $76(20 \%)$ & $2(14 \%)$ & $74(20 \%)$ & 1.00 \\
\hline Subclavian, $n(\%)$ & $5(1 \%)$ & $0(0 \%)$ & $5(1 \%)$ & 1.00 \\
\hline Valve type & & & & 0.17 \\
\hline Medtronic CoreValve, $n$ (\%) & $224(58 \%)$ & $11(79 \%)$ & $213(57 \%)$ & \\
\hline Edwards SAPIEN valve, $n(\%)$ & $165(42 \%)$ & $3(21 \%)$ & $162(43 \%)$ & \\
\hline \multicolumn{5}{|l|}{ Implantation specifications } \\
\hline Predilation $\geq 2, n(\%)$ & $56(14 \%)$ & $4(29 \%)$ & $52(14 \%)$ & 0.13 \\
\hline Post-dilation $\geq 1, n(\%)$ & $108(28 \%)$ & $7(50 \%)$ & $101(27 \%)$ & 0.072 \\
\hline $\begin{array}{l}\text { Implantation attempts }>1, \mathrm{n} \\
(\%)\end{array}$ & $33(9 \%)$ & $4(29 \%)$ & $29(8 \%)$ & 0.023 \\
\hline Valve in series, $\mathrm{n}(\%)$ & $7(2 \%)$ & $1(7 \%)$ & $6(2 \%)$ & 0.23 \\
\hline \multicolumn{5}{|l|}{ Revascularisation } \\
\hline Concomitant PCl, n (\%) & $63(16 \%)$ & $2(14 \%)$ & $6(16 \%)$ & 1.00 \\
\hline Staged PCI, n (\%) & $35(9 \%)$ & $0(0 \%)$ & $35(9 \%)$ & 0.63 \\
\hline
\end{tabular}

vs. $4 \%, \mathrm{OR}_{\text {adjusted }} 2.6,95 \%$ CI $0.3-22.8, \mathrm{p}=0.52$ ) and access site complications (major vascular access site complications $0 \%$ vs. $8 \%, \mathrm{OR}_{\text {crude }} 0.6,95 \%$ CI $0.0-3.7, \mathrm{p}=0.64$ ) between patients with and without CVA.
Table 3. Antithrombotic regimen at discharge.

\begin{tabular}{|l|c|c|c|c|} 
& $\begin{array}{c}\text { All patients } \\
(\mathrm{n}=389)\end{array}$ & $\begin{array}{c}\text { CVA } \\
(\mathrm{n}=14)\end{array}$ & $\begin{array}{c}\text { No CVA } \\
(\mathrm{n}=375)\end{array}$ & $\boldsymbol{p}$-value \\
\hline Aspirin, $\mathrm{n}(\%)$ & $286(80 \%)$ & $7(88 \%)$ & $279(80 \%)$ & 1.00 \\
\hline Clopidogrel, $\mathrm{n}(\%)$ & $257(72 \%)$ & $6(75 \%)$ & $251(72 \%)$ & 1.00 \\
\hline Aspirin and clopidogrel, $n(\%)$ & $222(62 \%)$ & $5(63 \%)$ & $217(62 \%)$ & 1.00 \\
\hline Oral anticoagulation, $\mathrm{n}(\%)$ & $90(25 \%)$ & $2(25 \%)$ & $88(25 \%)$ & 1.00 \\
\hline Oral anticoagulation and aspirin, $\mathrm{n}(\%)$ & $40(11 \%)$ & $1(13 \%)$ & $39(11 \%)$ & 1.00 \\
\hline Oral anticoagulation and clopidogrel, $\mathrm{n}(\%)$ & $32(9 \%)$ & $1(13 \%)$ & $31(9 \%)$ & 0.53 \\
\hline
\end{tabular}

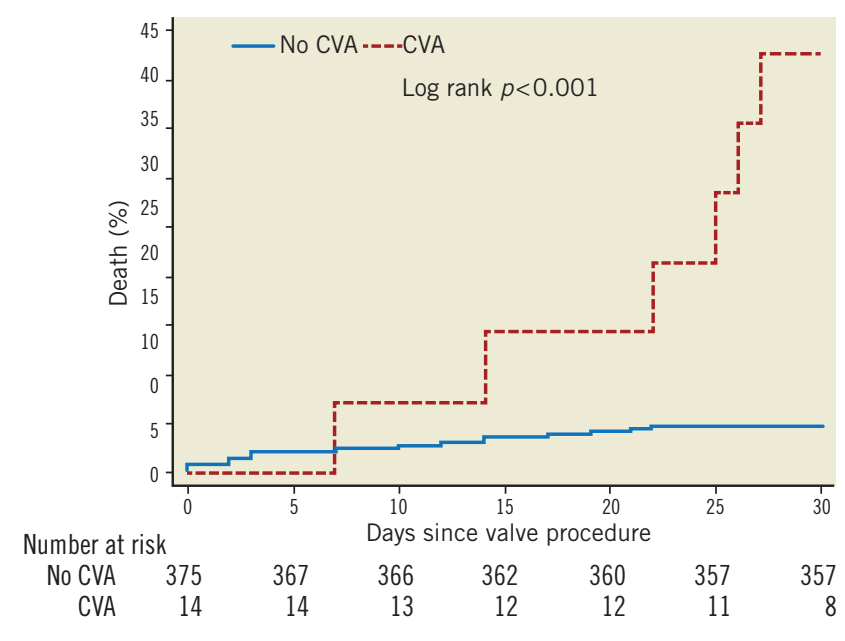

Figure 2. Cumulative incidence of all-cause mortality among patients with and without cerebrovascular accidents within 30 days after transcatheter aortic valve implantation. Patients without cerebrovascular event (blue line, no CVA) and patients with cerebrovascular events (red line, CVA).

Table 4. Clinical outcomes at 30 days of follow-up according to VARC.

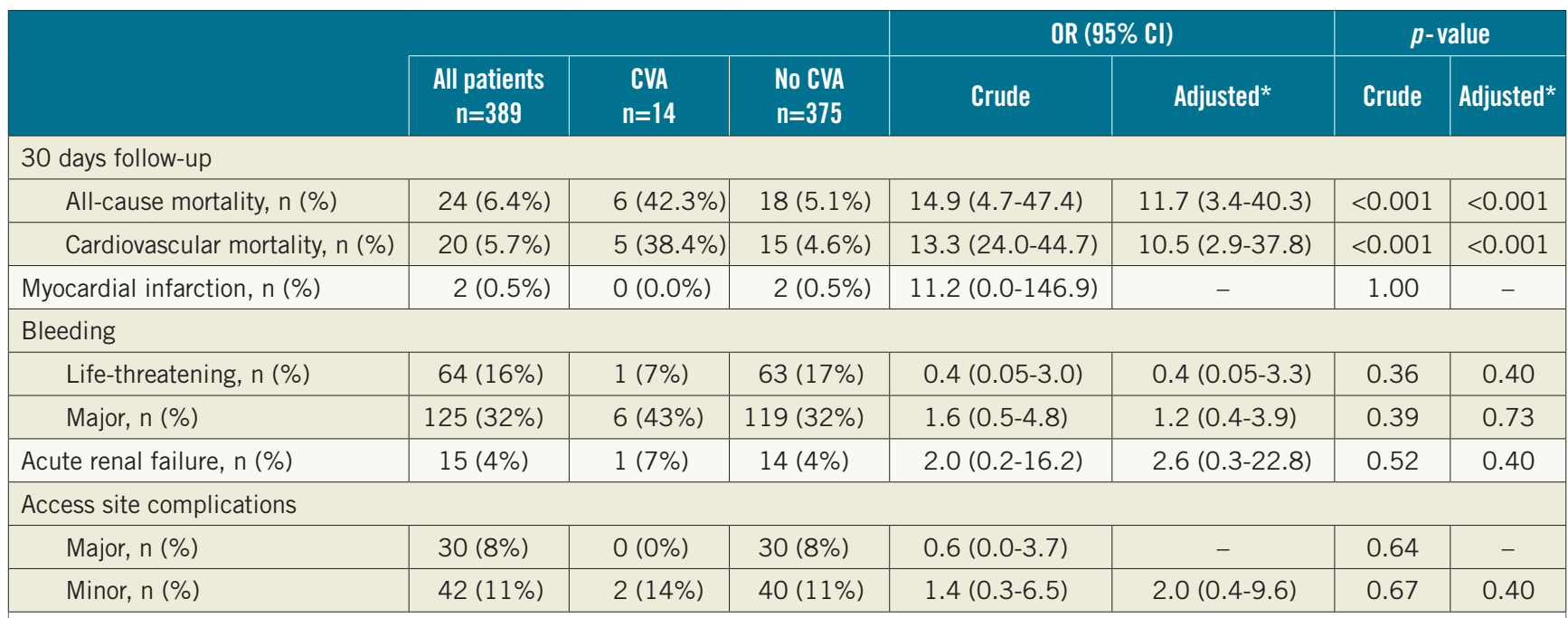

Depicted are odds ratios (OR) from logistic regression for all-cause death, cardiovascular death, bleeding, acute renal failure and minor access site complications. For myocardial infarction and major vascular complications odds ratios (OR) are used from exact logistic regression analysis. *Adjusted for body mass index and chronic obstructive pulmonary disease. 
Table 5. Characteristics of patients with cerebrovascular events.

\begin{tabular}{|c|c|c|c|c|l|l|l|}
\hline Patient & $\begin{array}{c}\text { Patient in } \\
\text { series }\end{array}$ & Age & $\begin{array}{c}\text { Access } \\
\text { route }\end{array}$ & $\begin{array}{c}\text { Time after } \\
\text { TAVI }\end{array}$ & $\begin{array}{c}\text { Type of CVA } \\
\text { (VARC) }\end{array}$ & \multicolumn{1}{|c|}{ Symptoms } & \multicolumn{1}{|c|}{ Classification } \\
\hline$\# 1$ & $\# 47$ & 91 & TF & 14d & Major stroke & $\begin{array}{l}\text { Left facial palsy and left side accentuated arm } \\
\text { paresis }\end{array}$ & Uncertain \\
\hline$\# 2$ & $\# 49$ & 83 & TF & 23d & Major stroke & Left-sided hemiparesis & Uncertain \\
\hline$\# 3$ & $\# 105$ & 90 & TF & 1d & Major stroke & Left-sided hemiparesis & Lacunar type (new multifocal spots) \\
\hline$\# 4$ & $\# 114$ & 77 & TA & ld & Major stroke & Left side accentuated arm paresis & Lacunar type (old multifocal spots) \\
\hline$\# 5$ & $\# 133$ & 76 & TF & 1d & Major stroke & Leg accentuated lack of strength & Lacunar type (new multifocal spots) \\
\hline$\# 6$ & $\# 172$ & 81 & TF & 0d & Major stroke & Right facial palsy, arm paresis and stupor & Uncertain \\
\hline$\# 7$ & $\# 181$ & 64 & TA & 4d & Major stroke & Left side accentuated neglect & Cortical type (new multifocal spots) \\
\hline$\# 8$ & $\# 192$ & 86 & TF & 1d & Major stroke & Left-sided hemiparesis & Lacunar type (new multifocal spots) \\
\hline$\# 9$ & $\# 214$ & 77 & TF & 0d & Major stroke & Left-sided hemiparesis & Lacunar type (old multifocal spots) \\
\hline$\# 10$ & $\# 220$ & 86 & TF & 13d & Major stroke & Right arm paresis & Lacunartical type (old single spots) \\
\hline$\# 11$ & $\# 264$ & 84 & TF & 0d & Major stroke & Apraxia & $\begin{array}{l}\text { Lacunar type (neuroradiological intervention with } \\
\text { extraction of thrombus material and local } \\
\text { thrombolysis resulting in full neurological recovery) }\end{array}$ \\
\hline$\# 12$ & $\# 321$ & 78 & TF & 0d & Minor stroke & Left-sided hemiparesis, hemianopia and neglect & Uncertain \\
\hline$\# 13$ & $\# 368$ & 82 & TF & 0d & Minor stroke & Diplopia & Lacunar type (new multifocal spots) \\
\hline$\# 14$ & $\# 369$ & 85 & TF & 0d & Major stroke & Left-sided hemiparesis \\
\hline
\end{tabular}

\begin{tabular}{|c|c|c|c|c|c|c|}
\hline & \multirow[b]{2}{*}{ CVA events/n } & \multicolumn{2}{|c|}{ OR $(95 \% \mathrm{Cl})$} & \multirow{2}{*}{$\begin{array}{l}\text { Odds ratio }(95 \% \mathrm{Cl}) \\
.2 .512 .4816 \\
\end{array}$} & \multicolumn{2}{|c|}{$p$-value } \\
\hline & & Crude & Adjusted* & & Crude & Adjusted* \\
\hline \multicolumn{7}{|c|}{ Body mass index group } \\
\hline$\geq 25 \mathrm{~kg} / \mathrm{m}^{2}$ & $4 / 212$ & $0.32(0.10-1.04)$ & $0.78(0.66-0.92)$ & $\mathbf{a}$ & 0.06 & 0.01 \\
\hline$<25 \mathrm{~kg} / \mathrm{m}^{2}$ & $10 / 177$ & & & & & \\
\hline \multicolumn{7}{|c|}{ Chronic obstructive pulmonary disease } \\
\hline Yes & $5 / 72$ & $2.85(0.90-8.97)$ & $4.73(1.33-16.79)$ & $\square$ & 0.07 & 0.02 \\
\hline No & $8 / 133$ & & & & & \\
\hline \multicolumn{7}{|c|}{ Implantation attempts >1 } \\
\hline Two or more & $4 / 33$ & $4.77(1.41-16.16)$ & $8.32(2.08-33.26)$ & $\longrightarrow$ & 0.01 & 0.003 \\
\hline One & $10 / 356$ & & & & & \\
\hline \multicolumn{7}{|l|}{ Previous stroke } \\
\hline Yes & $3 / 30$ & $3.52(0.92-13.36)$ & $1.87(0.33-10.62)$ & $\square$ & & \\
\hline No & $11 / 359$ & & & & & \\
\hline \multicolumn{7}{|l|}{ Post-dilation $\geq 1$} \\
\hline One or more & $7 / 108$ & $2.69(0.92-7.87)$ & $2.00(0.62-6.49)$ & $-\square$ & 0.07 & 0.25 \\
\hline Zero & $7 / 279$ & & lower & $\stackrel{\longmapsto}{\text { higher ris }}$ & & \\
\hline
\end{tabular}

Figure 3. Crude and adjusted odds ratios of the endpoint cerebrovascular accidents within 30 days of transcatheter aortic valve implantation stratified across subgroups.

\section{Discussion}

The present study reporting on the frequency, timing and impact of periprocedural CVA among patients undergoing TAVI has the following main findings:
- The incidence of CVA after TAVI was low in this elderly, highrisk patient population with the vast majority of events occurring during the immediate periprocedural period.

- Independent predictors of periprocedural CVA comprised the 
number of device implantation attempts, chronic obstructive pulmonary disease and body mass index below $25 \mathrm{~kg} / \mathrm{m}^{2}$.

- A CVA was associated with a 10 -fold increased risk of overall and cardiovascular mortality within 30 days.

The incidence of CVA in this elderly, high-risk patient population undergoing TAVI amounted to $3.6 \%$ at 30 days. This rate is consistent with previously published reports of large-scale registries ${ }^{8}$ and has to be interpreted in the context of the risk profile of octogenarians with a high prevalence of cardiovascular risk factors, coronary and peripheral vascular disease, and atrial fibrillation. It is also comparable to rates of CVA as reported in the randomised Placement of Transcatheter Aortic Valves (PARTNER A and B) trial. Compared with medical treatment, TAVI was associated with a somewhat higher risk of major stroke at 30 days in PARTNER B (5.0\% versus $1.1 \%, \mathrm{p}=0.06)$, whereas there were no differences between TAVI and SAVR during the periprocedural period in PARTNER A (3.8\% versus $2.1 \%, \mathrm{p}=0.20)$.

CVA during the periprocedural period of TAVI may be related to specific patient and procedural characteristics. Classical risk factors for stroke like age, gender, arterial hypertension, atrial fibrillation or diabetes mellitus ${ }^{9}$ were not predictive for a CVA but patients with CVA more often had a low body mass index, chronic obstructive pulmonary disease and experienced a stroke in their past medical history.

Several studies have reported a higher incidence of stroke among patients with new onset atrial fibrillation after TAVI. Along this line, Amat-Santos et al have observed an incidence of new-onset atrial fibrillation of $32 \%$ among patients undergoing TAVI, which was associated with an increased risk of stroke and systemic embolism. In contrast, new-onset atrial fibrillation was observed only in $7 \%$ of patients in the present study population, predominantly undergoing TAVI via the transfemoral access route. The rate of new onset of atrial fibrillation in the present study is well in line with the $8.6 \%$ incidence observed in the PARTNER cohort A study, and it did not emerge as an independent predictor of stroke. Nevertheless, new-onset atrial fibrillation is known to affect clinical outcome adversely following surgical aortic valve replacement ${ }^{10,11}$, and therefore preventive strategies and optimal anticoagulation regimens among affected patients remain to be determined.

The majority of CVAs accumulate in the early periprocedural period $^{1,2,5}$. Thromboembolic events with cerebrovascular injury may occur at various stages during TAVI: 1) retrograde passage of the calcified aortic valve ${ }^{12,13}$; 2) predilatation of the native valve; 3) advancement of the delivery catheter through the aortic arch and deployment of the prosthesis ${ }^{14}$. Previous studies reported on the detection of new intracranial lesions distributed in both hemispheres using diffusionweighted magnetic resonance neuroimaging suggesting a high prevalence of cerebral thromboembolism during TAVI ${ }^{15-18}$. The concept of cerebral embolism is further supported by transcranial Doppler ultrasonography studies recording a high number of high-intensity transient signals (HITS) during the various stages of TAVI ${ }^{14,19}$. Although the majority of intracranial lesions identified by magnetic resonance imaging remained clinically silent, an adverse effect of cerebral embolism resulting in behavioural or cognitive impairment has not been sufficiently investigated to date.

To the best of our knowledge, this study is the first report on the association of procedural steps of TAVI and the risk of stroke. The number of device implantation attempts emerged as an independent predictor of stroke and was associated with an eight-fold increased risk of periprocedural CVA in the present study. This observation suggests that any additional manipulation in the aortic arch, the ascending aorta or the native aortic valve may contribute to an increased risk of periprocedural stroke but also point to the potential of preventive strategies during the periprocedural period. Embolic protection devices, recently introduced in clinical practice, either deviate or filter thromboembolic debris during the intervention. Three dedicated devices for the reduction of CVA have been tested in human: the Embrella embolic protection device (Edwards Lifesciences, Irvine, CA, USA ${ }^{20}$ delivered through the right radial artery has a specific heparin-coated polyurethane membrane which is designed to cover the ostia of the brachiocephalic trunk and the left common carotid artery, thereby deflecting embolic debris from the cerebral circulation. The SMT Shimon Embolic protection filter (SMT Medical, Herzliya Pituach, Israel) is another embolic deflection device, introduced femorally. The Claret CE Pro ${ }^{\mathrm{TM}}$ (Claret Medical, Inc., Santa Rosa, CA, USA) $)^{21}$ is designed to capture debris in two filters placed in the brachiocephalic trunk and the left common carotid artery. It provides the possibility of retrieving debris and not only deflecting the embolic material. Recent studies demonstrated the feasibility of these devices and the ease of use. Clinical trials proving a benefit with respect to reducing the CVA event rate are however missing. Therefore, the routine use of cerebral protection devices cannot be recommended so far and requires careful scrutiny. Another focus of CVA prevention is an improvement of antithrombotic and antiplatelet regimens. An optimal antiplatelet therapy carries the potential to reduce not only the periprocedural risk but also the long-term risk of a CVA in this high-risk patient population. Following surgical aortic valve replacement using a bioprosthesis, a low dose acetylsalicylic acid $(100 \mathrm{mg})$ regimen is recommended whereas dual antiplatelet therapy with acetylsalicylic acid in combination with clopidogrel ( $75 \mathrm{mg}$ per day) for six months represents the favoured strategy after TAVI. Oral anticoagulation with the use of vitamin $\mathrm{K}$ antagonists or direct thrombin inhibitors in addition to low dose aspirin are considered as the most favourable treatment options in patients with atrial fibrillation. Further studies are required to determine the optimal medical treatment strategy in this elderly patient population with a high risk of stroke undergoing TAVI.

Similar to previous reports, patients suffering from periprocedural CVA had impaired clinical outcome in terms of all-cause and cardiovascular mortality in our study. Of note, the risk of death was increased more than 10-fold in an adjusted analysis highlighting the deleterious effect of a cerebrovascular event on clinical outcome. Moreover, CVA abolishes the improvement of symptoms and other quality of life measures usually observed after TAVI. 
The current study has some limitations that might influence the significance and the strength of the results. First, the study population is based on the experience of a single, tertiary care centre. This limits the generalisability of the findings and may not apply to other centres using a different mixture of devices and procedural and post-procedural anticoagulation regimens. Second, the low rate of cerebrovascular events has to be considered when interpreting the results of the present study and may result in over-fitting in the regression model. However, we report both crude and adjusted analyses of all outcome variables and found results to be robust, supporting the conclusions of this study. Third, prior to the advent of the VARC criteria, cerebrovascular accidents were recorded according to the clinical neurological examination and cerebral imaging results, as performed by a board-certified neurologist and adjudicated by the interdisciplinary clinical event committee. By January 2011, all endpoints including cerebrovascular accidents were re-adjudicated according to the clinical endpoint definitions proposed by VARC and since then the Modified Rankin Scale was prospectively recorded and used for assessment of stroke severity. Finally, we did not record the time required to cross the aortic valve retrogradely or the extent of calcification of the aortic valve, the ascending aorta and the aortic arch, which may have an important impact on the periprocedural risk of stroke.

\section{Conclusion}

Cerebrovascular accidents in TAVI patients occur predominantly during the periprocedural period, are independently predicted by multiple implantation attempts of the bioprosthesis and significantly impair clinical outcome as reflected by an increased mortality rate.

\section{Conflict of interest statement}

$\mathrm{P}$. Wenaweser is proctor and receives honoraria from Medtronic CoreValve and Edwards Lifesciences. A. Khattab has received speaker honoraria and proctor fees from Medtronic CoreValve and Edwards Lifesciences. L. Buellesfeld is a consultant and proctor for Medtronic. S. Windecker has received honoraria and consultant fees from Edwards Lifesciences and Medtronic CoreValve. All other authors have no relationships relevant to the contents of this paper to disclose.

\section{References}

1. Leon MB, Smith CR, Mack M, Miller DC, Moses JW, Svensson LG, Tuzcu EM, Webb JG, Fontana GP, Makkar RR, Brown DL, Block PC, Guyton RA, Pichard AD, Bavaria JE, Herrmann HC, Douglas PS, Petersen JL, Akin JJ, Anderson WN, Wang D, Pocock S. Transcatheter aortic-valve implantation for aortic stenosis in patients who cannot undergo surgery. $N$ Engl J Med. 2010;363:1597-607.

2. Smith CR, Leon MB, Mack MJ, Miller DC, Moses JW, Svensson LG, Tuzcu EM, Webb JG, Fontana GP, Makkar RR, Williams M, Dewey T, Kapadia S, Babaliaros V, Thourani VH, Corso P, Pichard AD, Bavaria JE, Herrmann HC, Akin JJ,
Anderson WN, Wang D, Pocock SJ. Transcatheter versus surgical aortic-valve replacement in high-risk patients. $N$ Engl $\mathrm{J} \mathrm{Med}$. 2011;364:2187-98.

3. Reynolds MR, Magnuson EA, Wang K, Lei Y, Vilain K, Walczak J, Kodali SK, Lasala JM, O'Neill WW, Davidson CJ, Smith CR, Leon MB, Cohen DJ. Cost-Effectiveness of Transcatheter Aortic Valve Replacement Compared With Standard Care Among Inoperable Patients With Severe Aortic Stenosis: Results From the Placement of Aortic Transcatheter Valves (PARTNER) Trial (Cohort B). Circulation. 2012;125:1102-9.

4. Ussia GP, Barbanti M, Cammalleri V, Scarabelli M, Mule M, Aruta P, Pistritto AM, Imme S, Capodanno D, Sarkar K, Gulino S, Tamburino C. Quality-of-life in elderly patients one year after transcatheter aortic valve implantation for severe aortic stenosis. EuroIntervention. 2011;7:573-9.

5. Tay EL, Gurvitch R, Wijesinghe N, Nielispach F, Wood D, Cheung A, Ye J, Lichtenstein SV, Carere R, Thompson C, Webb JG. A high-risk period for cerebrovascular events exists after transcatheter aortic valve implantation. JACC Cardiovasc Interv. 2011;4: 1290-7.

6. Wenaweser P, Pilgrim T, Roth N, Kadner A, Stortecky S, Kalesan B, Meuli F, Bullesfeld L, Khattab AA, Huber C, Eberle B, Erdos G, Meier B, Juni P, Carrel T, Windecker S. Clinical outcome and predictors for adverse events after transcatheter aortic valve implantation with the use of different devices and access routes. $\mathrm{Am}$ Heart J. 2011;161:1114-24.

7. Leon MB, Piazza N, Nikolsky E, Blackstone EH, Cutlip DE, Kappetein AP, Krucoff MW, Mack M, Mehran R, Miller C, Morel MA, Petersen J, Popma JJ, Takkenberg JJ, Vahanian A, van Es GA, Vranckx P, Webb JG, Windecker S, Serruys PW. Standardized endpoint definitions for transcatheter aortic valve implantation clinical trials: a consensus report from the Valve Academic Research Consortium. Eur Heart J. 2011;32:205-17.

8. Eggebrecht H, Schmermund A, Voigtlander T, Kahlert P, Erbel R, Mehta RH. Risk of stroke after transcatheter aortic valve implantation (TAVI): a meta-analysis of 10,037 published patients. EuroIntervention. 2012 Mar 6 [Epub ahead of print].

9. D'Agostino RB, Wolf PA, Belanger AJ, Kannel WB. Stroke risk profile: adjustment for antihypertensive medication. The Framingham Study. Stroke. 1994;25:40-3.

10. Girerd N, Magne J, Pibarot P, Voisine P, Dagenais F, Mathieu P. Postoperative atrial fibrillation predicts long-term survival after aortic-valve surgery but not after mitral-valve surgery: a retrospective study. BMJ Open. 2011;1:e000385.

11. Filardo G, Hamilton C, Hamman B, Hebeler RF, Jr., Adams J, Grayburn P. New-onset postoperative atrial fibrillation and longterm survival after aortic valve replacement surgery. Ann Thorac Surg. 2010;90:474-9.

12. Omran H, Schmidt H, Hackenbroch M, Illien S, Bernhardt $P$, von der Recke G, Fimmers R, Flacke S, Layer G, Pohl C, Luderitz B, Schild H, Sommer T. Silent and apparent cerebral embolism after retrograde catheterisation of the aortic valve in valvular stenosis: a prospective, randomised study. Lancet. 2003;361:1241-6. 
13. Lund C, Nes RB, Ugelstad TP, Due-Tonnessen P, Andersen R, Hol PK, Brucher R, Russell D. Cerebral emboli during left heart catheterization may cause acute brain injury. Eur Heart $J$. 2005;26:1269-75.

14. Erdoes G, Basciani R, Huber C, Stortecky S, Wenaweser P, Windecker S, Carrel T, Eberle B. Transcranial Doppler-detected cerebral embolic load during transcatheter aortic valve implantation. Eur J Cardiothorac Surg. 2012;41:778-84.

15. Rodes-Cabau J, Dumont E, Boone RH, Larose E, Bagur R, Gurvitch R, Bedard F, Doyle D, De Larochelliere R, Jayasuria C, Villeneuve J, Marrero A, Cote M, Pibarot P, Webb JG. Cerebral embolism following transcatheter aortic valve implantation: comparison of transfemoral and transapical approaches. J Am Coll Cardiol. 2011;57:18-28.

16. Ghanem A, Muller A, Nahle CP, Kocurek J, Werner N, Hammerstingl C, Schild HH, Schwab JO, Mellert F, Fimmers R, Nickenig G, Thomas D. Risk and fate of cerebral embolism after transfemoral aortic valve implantation: a prospective pilot study with diffusion-weighted magnetic resonance imaging. J Am Coll Cardiol. 2010;55:1427-32.

17. Astarci P, Glineur D, Kefer J, D'Hoore W, Renkin J, Vanoverschelde JL, El Khoury G, Grandin C. Magnetic resonance imaging evaluation of cerebral embolization during percutaneous aortic valve implantation: comparison of transfemoral and transapical approaches using Edwards Sapiens valve. Eur J Cardiothorac Surg. 2011;40:475-9.

18. Arnold M, Schulz-Heise S, Achenbach S, Ott S, Dorfler A, Ropers D, Feyrer R, Einhaus F, Loders S, Mahmoud F, Roerick O, Daniel WG, Weyand M, Ensminger SM, Ludwig J. Embolic cerebral insults after transapical aortic valve implantation detected by magnetic resonance imaging. JACC Cardiovasc Interv. 2010;3: 1126-32.

19. Drews T, Pasic M, Buz S, Unbehaun A, Dreysse S, Kukucka M, Mladenow A, Hetzer R. Transcranial Doppler sound detection of cerebral microembolism during transapical aortic valve implantation. Thorac Cardiovasc Surg. 2011;59:237-42.

20. Nietlispach F, Wijesinghe N, Gurvitch R, Tay E, Carpenter JP, Burns C, Wood DA, Webb JG. An embolic deflection device for aortic valve interventions. JACC Cardiovasc Interv. 2010;3: 1133-8.

21. Naber CK, Ghanem A, Abizaid AA, Wolf A, Sinning JM, Werner N, Nickenig G, Schmitz T, Grube E. First-in-man use of a novel embolic protection device for patients undergoing transcatheter aortic valve implantation. EuroIntervention. 2012 Mar 9. pii: 20120213-01. [Epub ahead of print] 